\title{
Super enhancer associated RAI14 is a new potential biomarker in lung adenocarcinoma
}

\author{
Chongze Yuan ${ }^{1,2, *}$, Hong Hu${ }^{1,2, *}$, Muyu Kuang ${ }^{1,2, *}$, Zongwei Chen ${ }^{4}$, Xiaoting Tao ${ }^{1,2}$, \\ Shengjian Fang ${ }^{1,2}$, Yihua Sun ${ }^{1,2}$, Yawei Zhang ${ }^{1,2}$ and Haiquan Chen ${ }^{1,2,3}$ \\ ${ }^{1}$ Department of Thoracic Surgery, Fudan University Shanghai Cancer Center, Shanghai, China \\ ${ }^{2}$ Department of Oncology, Shanghai Medical College, Fudan University, Shanghai, China \\ ${ }^{3}$ Institutes of Biomedical Sciences, Fudan University, Shanghai, China \\ ${ }^{4}$ Department of Thoracic Surgery, Zhongshan Hospital, Shanghai, China \\ *These authors have contributed equally to this work \\ Correspondence to: Yihua Sun, email: Sun_yihua76@hotmail.com \\ Yawei Zhang, email: zhangyawei68@hotmail.com \\ Haiquan Chen, email: hqchen1@yahoo.com
}

Keywords: Iung cancer; ChIP-seq; super enhancer; RAll4; targeted therapy

Abbreviations: SE: super enhancer; TE: typical enhancer; TKIs: tyrosine kinase inhibitors; ChIP-seq: Chromatin Immunoprecipitation followed by high-throughput DNA sequencing; NSCLC: non-small cell lung cancer

Received: December 23, $2016 \quad$ Accepted: September 23, $2017 \quad$ Published: October 27, 2017

Copyright: Yuan et al. This is an open-access article distributed under the terms of the Creative Commons Attribution License 3.0 (CC BY 3.0), which permits unrestricted use, distribution, and reproduction in any medium, provided the original author and source are credited.

\section{ABSTRACT}

Purpose: Tyrosine kinase inhibitors (TKIs) are widely used to treat lung adenocarcinoma patients with EGFR mutations or ALK-fusions. However, patients with wild-type genes or TKIs-resistant mutations lack effective therapeutic targets. Extensive studies reveal that super enhancer (SE), a large cis-regulatory element, is associated with key oncogenes in a variety of cancers. By comparing the effect of SE on lung adenocarcinoma cell lines with normal cell line, this work attempts to find new biomarkers and potential therapeutic targets for lung adenocarcinoma.

Experimental Design: Chromatin Immunoprecipitation (ChIP) followed by highthroughput DNA sequencing (ChIP-seq) of H3K27ac (acetylation on lysine 27 of histone 3) was performed in lung adenocarcinoma cell lines SPC-A1 and SCH-1153. The differences in SE distribution were then analyzed among SPC-A1, SCH-1153, A549 and normal human lung fibroblasts (NHLF) to identify SE-associated oncogenes. The expression of SE-associated oncogenes was then detected by RNA-seq and further verified in 71 patients by real-time PCR.

Results: SE associated with many new oncogenes in lung adenocarcinoma, among which, RAI14 was up-regulated in A549 and 31 of 71 patients. High expression of RAI14 could inhibit cell proliferation, indicating its potential as a new biomarker for lung adenocarcinoma.

\section{INTRODUCTION}

One of the most malignant tumors yet discovered, lung cancer has been the leading cause of mortality of male worldwide. The lung cancer is also the most common cancer and leading cause of death in China, with an incidence of 733.3/100,000 and mortality of 610.2/100,000 separately [1]. Numerous genomic alterations have been found in correlation with oncogenesis and cancer progress, such as EGFR mutations, $A L K$-fusions, and $K R A S$ mutations. EGFR mutations were found in $30 \%$ to $60 \%$ of Asian patients and $10 \%$ to $20 \%$ of Caucasian patients with NSCLC (non-small cell lung cancer), while $A L K$ fusions were found in $2 \%$ to $5 \%$ of patients [2-5]. Patients with $E G F R$ mutations or $A L K$-fusions are recommended to receive targeted therapy of tyrosine kinase inhibitors 
(TKIs), which significantly prevents the progression of cancer and improves patients' prognosis [6].

$K R A S$ mutations maybe the most frequent gene abnormalities in lung adenocarcinoma since about $3 \%$ to $8 \%$ of Chinese patients and $15 \%$ to $25 \%$ of Caucasian patients were KRAS mutations positive [7-10]. KRAS mutations are usually considered as poor prognosis biomarkers mainly because these mutations cause nonresponse to EGFR-TKI treatment [11]. MEK inhibitors have been approved for the treatment of KRAS mutations positive colorectal cancer patients, but they did not show priority to docetaxel in patients with previously treated $K R A S$ mutations positive NSCLC [12].

In general, the treatment of patients without $E G F R$ mutations/ALK-fusions or with KRAS mutations is still challenging due to the lack of effective therapeutic targets. Super enhancer (SE) is a large cis-regulatory element recently put forward which is related to key cell identity genes and diseases. Cancer cell could acquire and activate carcinogenic SE by chromosomal rearrangement, focal amplification and over-expression of transcription factors [13]. Over-expression of SEassociated oncogenes play important roles in tumor pathogenesis. Associated with new oncogenes, abnormal SEs help us find potential therapeutic targets. In this study, we selected 3 lung adenocarcinoma cell lines SPC-A1, $\mathrm{SCH}-1153$ and A549, which were all inappropriate for TKIs due to the lack of EGFR mutations/ALK-fusions or possessing KRAS mutations. With the use of the SE maker H3K27ac (acetylation on lysine 27 of histone 3), we performed Chromatin Immunoprecipitation followed

A
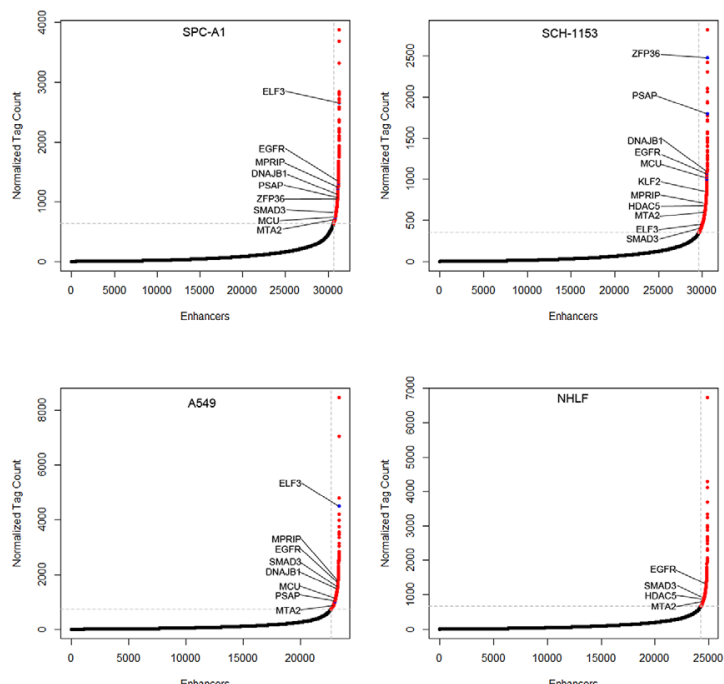

by high-throughput DNA sequencing (ChIP-seq) in SPC-A1 and SCH-1153 [14, 15]. After comparing the ChIP-seq data with online data of A549 and NHLF, we found 1453 tumor-associated SEs. Based on the mRNA expression detected in SE-associated genes in both cell lines and tissue samples, we identified $R A I 14$ as a novel SE-associated biomarker and potential therapeutic target in lung adenocarcinoma.

\section{RESULTS}

\section{Super enhancer landscape in SPC-A1, SCH- 1153, A549 and NHLF}

To investigate the SE distribution in lung adenocarcinoma cells and normal cells, we utilized $\mathrm{H} 3 \mathrm{~K} 27 \mathrm{ac}$ as our SE marker and performed ChIP-seq in SPC-A1 and SCH-1153 with the use of H3K27ac specific antibody [16-18]. The raw ChIP-seq data of A549 and NHLF using the same of antibody came from ENCODE. The ChIP-seq data of 4 cell lines were then analyzed to identify H3K27ac enrichment regions (peaks). After stitching peaks in $12.5 \mathrm{~kb}$ and ranking, we identified 655 , 984, 701 and 603 super enhancers in SPC-A1, SCH1153, A549 and NHLF respectively [19, 20] (Figure 1A, 1B). Consistent with previous studies, genes with critical functions were SE-associated in 4 cell lines, such as ZFP36, ELF3, SMAD3 and HDAC5 (Supplementary-1). Furthermore, lots of well-studied oncogenes were also dominated by SE, such as MTA2, EGFR and KLF2 (Supplementary-1). In order to understand the biological

\section{B}
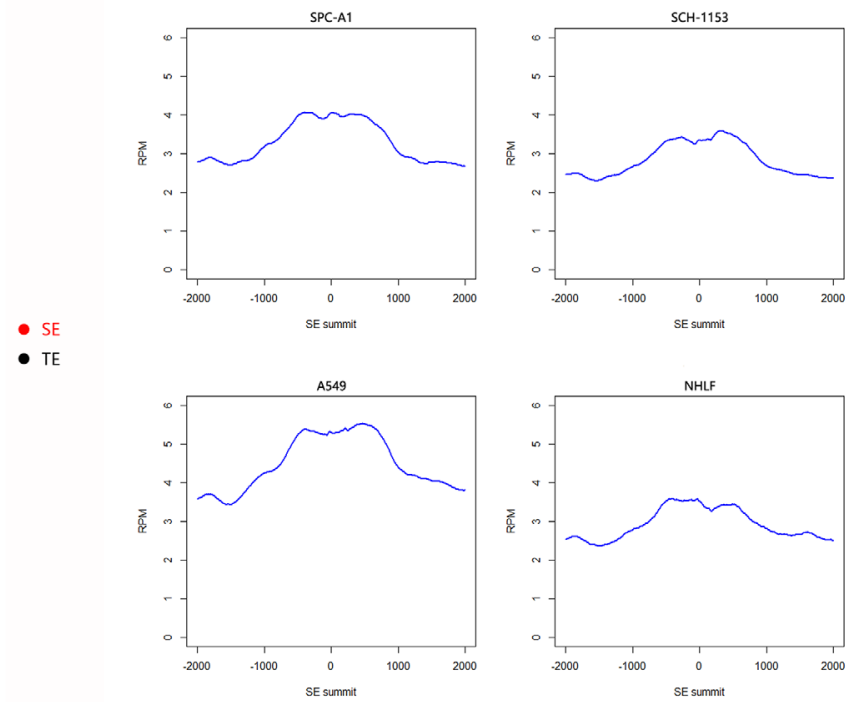

Figure 1: SE scatter plots and histograms of H3K27ac signal distribution in 4 cell lines. (A), Scatter plots of SEs in 4 cell lines. All stitched regions were ranked by H3K27ac signal, SE and TE were in different colors as indicated. (B), Bimodal H3K27ac signal distribution at identified SE regions. SE: super enhancer, TE: typical enhancer. 
features of SE, we performed GO and KEGG analysis of SE-associated genes. In GO analysis, compared with NHLF, more tumor-related biological processes were enriched in 3 lung adenocarcinoma cell lines, including cell proliferation, migration and differentiation (Figure 2A). The majority of SE-associated genes enriched in NHLF were essential genes for cell metabolism and development, which were also enriched in SPC-A1, SCH1153 and A549. Similar to GO analysis, critical pathways like cell cycle and focal adhesion were found in 4 cell lines, while more tumor-related pathways were enriched in SPC-A1, SCH-1153 and A549 (Figure 2B).

\section{Tumor-associated SEs control oncogenes' expression in lung adenocarcinoma}

SE is a complicated element that is occupied by high density of transcription factors, mediators and other components, which are all necessary to its function of transactivation [19]. SE is not immutable, extracellular or intracellular environmental alterations could change SE landscape and influence gene transcription [21, 22]. To comprehensively investigate SE diversity in 4 cell lines, we performed H3K27ac enrichment analysis at all identified SE regions (Figure 3A, Supplementary-2).

A
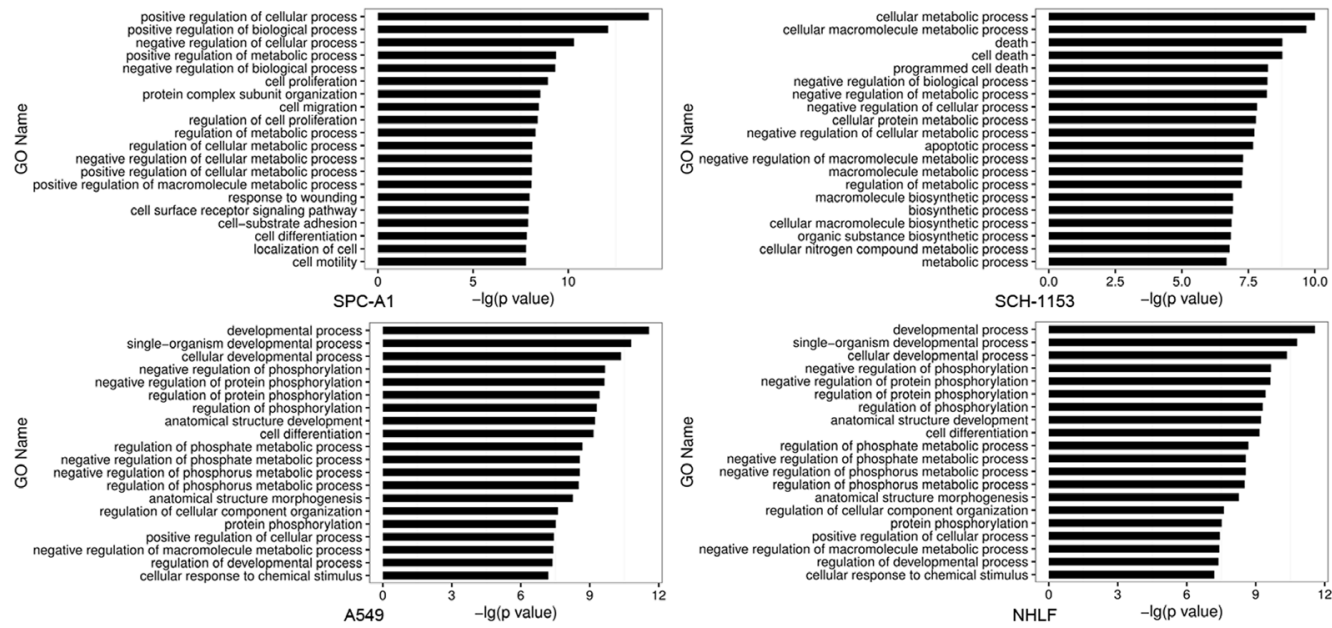

B
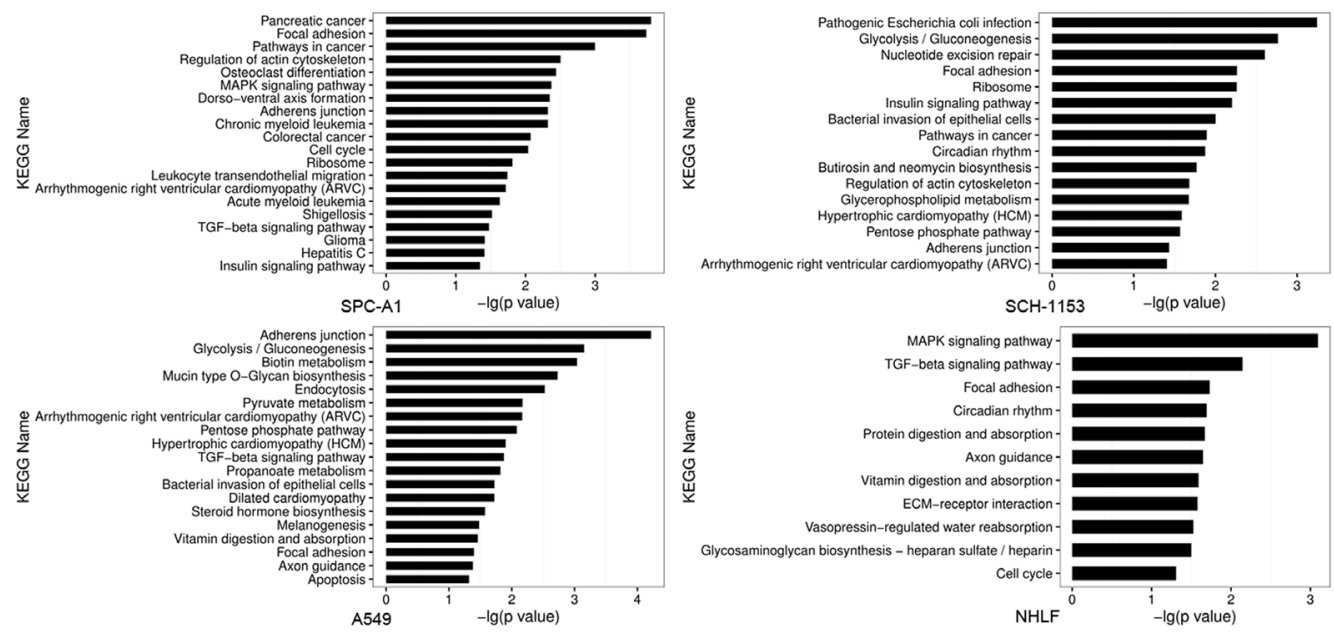

Figure 2: GO and KEGG analysis of SE-associated genes in 4 cell lines. (A), GO analysis for SE-associated genes in 4 cell lines. Ordinate comments indicated the biological processes that genes may be involved in, the abscissa values mean the statistical significance of processes. All processes listed were statistically significant with $\mathrm{p}<0.05$. (B), KEGG analysis for SE-associated genes in 4 cells. Ordinate comments indicated the pathways that genes may be involved in, the abscissa values mean the statistical significance. All the pathways listed were statistically significant with $\mathrm{p}<0.05$. 
As shown by our results, a small portion of identified SE regions exhibited similar $\mathrm{H} 3 \mathrm{~K} 27 \mathrm{ac}$ enrichment, but at most regions, significant enrichment diversities were observed across 4 cell lines. In our study, we identified 2034 SE regions in 4 cell lines, among which 1464 SEs were cell-type specific (Figure 3B). These cell-type specific SEs were associated with various genes and may collaboratively contribute to cell features. 43 of 2034 SEs, only $2.1 \%$ of all identified SEs were shared by 4 cell lines, regulating genes which were involved in critical cell functions such as transcriptional regulation, cell proliferation and signal transduction. To search
A

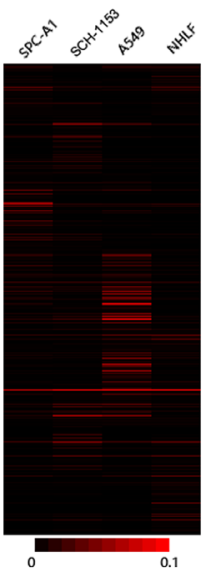

C
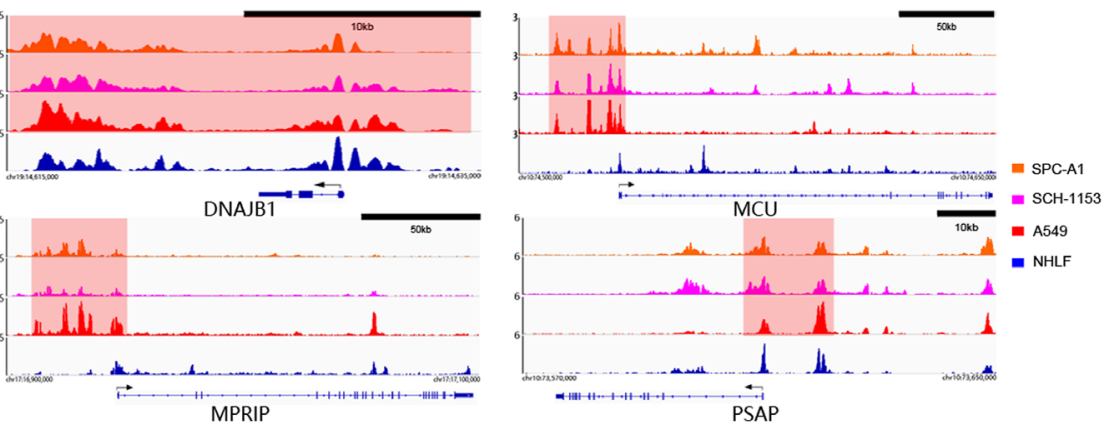

D

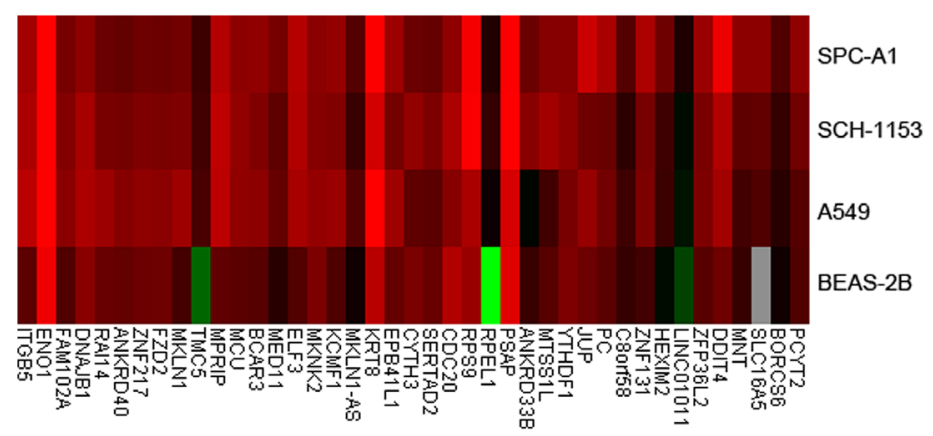

Figure 3: The H3K27ac enrichment differences, SE distribution, ChIP-seq binding profiles and associated genes' expression in 4 cell lines. (A), Heat map showed H3K27ac enrichment at all identified SE regions in 4 cell lines. (B), Venn diagram showed SE distributions in 4 cell lines. The number and percentage of SEs shared by different cell lines were as indicated. (C), ChIP-seq binding profiles of $\mathrm{H} 3 \mathrm{~K} 27 \mathrm{ac}$ at DNAJB1, MCU, MPRIP and PSAP in 4 cell lines as indicated. Gene models were depicted below the binding profiles and SEs were marked out with light red background. (D), Heat map showed expression of 38 tumor-specific SE-associated genes, RAI14, ZNF131 and TMC5 in SPC-A1, SCH-1153, A549 and BEAS-2B. 
new oncogenes, we mainly focused on the 1453 tumorassociated SEs which were not identified in NHLF, especially the 41 SEs shared by 3 lung adenocarcinoma cell lines. The SE-associated transcriptional dysregulation may facilitate tumor pathogenesis. And to efficiently identify potential SE-associated oncogenes, we hypothetically regarded these 41 SEs as tumor-specific SEs. In 41 tumor-specific SEs, several SEs with significant $\mathrm{H} 3 \mathrm{~K} 27 \mathrm{ac}$ enrichment were close to previously reported tumor-related genes, like $M C U, M P R I P$ and PSAP (Figure 3C, Supplementary-2).

To investigate whether these potential oncogenes exhibited abnormal expression in lung adenocarcinoma, we performed RNA-seq in SPC-A1, SCH-1153, A549 and human bronchial epithelial cell line (BEAS-2B), instead of NHLF (Supplementary Figure 1). In 38 tumor-specific SEassociated genes, 37 genes showed significantly elevated expression in at least 1 cancer cell line, including $D N A J B 1$, $M C U, M P R I P$ and PSAP (Figure 3D). DNAJB1 is a wellstudied oncogene that could promote cell proliferation and has also been reported as an SE-associated oncogene in esophageal squamous cell carcinoma [23]. In our study, DNAJB1 was also SE-associated, but the H3K27ac enrichment just slightly decreased in NHLF
(Supplementary-2). In a variety of cancers, these 4 upregulated genes (DNAJB1, MCU, MPRIP and PSAP) have been reported to be related to drug-resistance processes, cell death, cancer invasion and metastasis [24-27].

Besides these 37 genes, RAI14 (SE-associated in A549), ZNF131 (SE-associated in SPC-A1) and TMC5 (non-SE-associated) were up-regulated in lung cancer, which were also potential biomarkers of lung adenocarcinoma (Figure 3D). The complexity of transcriptional regulation is highly likely to be a main reason causing the deviation between SE prediction and associated gene expression, as our results showed. However, our results still proved the SE's intensive regulation of transcription was irreplaceable.

\section{$R A I 14$ is a potential biomarker of lung adenocarcinoma}

Our results of SE distribution and associated gene expression revealed several oncogenes as potential biomarkers. To evaluate the possibility for clinical application, we tested the expression of DNAJB1, $M C U$, MPRIP, PSAP, RAI14, ZNF131 and TMC5 in 71 lung adenocarcinoma samples and paired adjacent normal

\section{A}

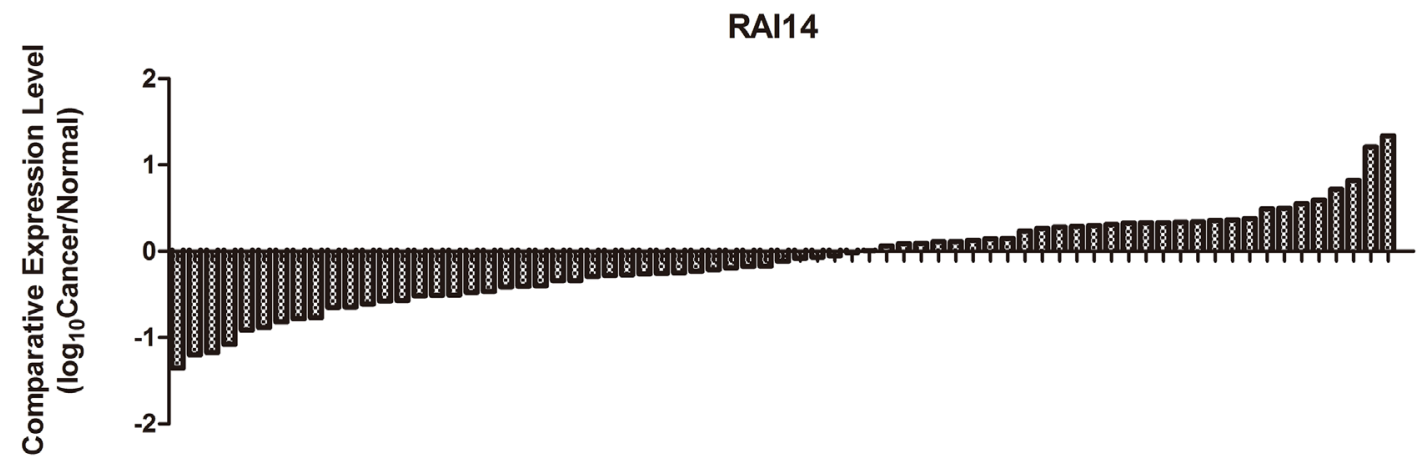

B
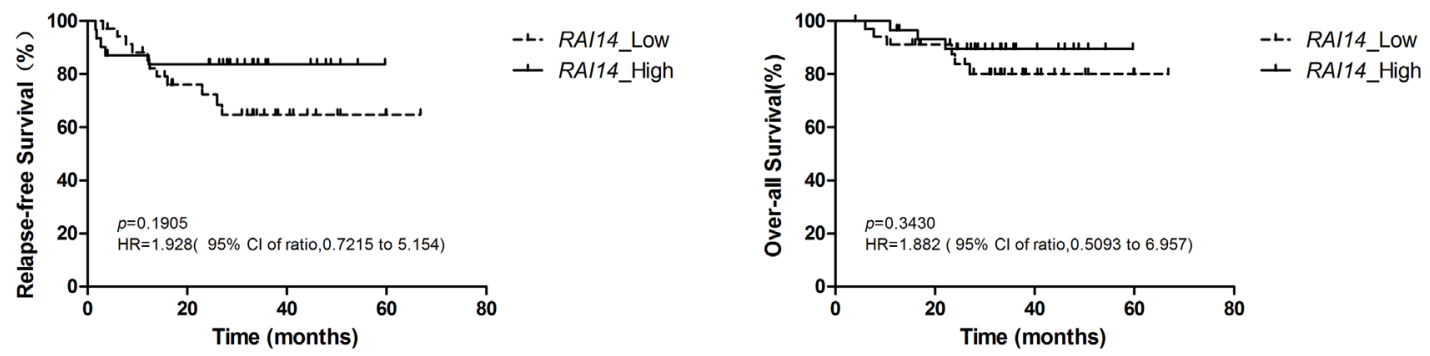

Figure 4: $R A I 14$ expression status in 71 patients and cumulative probability of relapse-free survival and over-all survival for patients with lung adenocarcinoma. (A), RAII4 expression status in 71 patients. The final result was displayed in the form of $\log _{10}$ as the Y-Axis label indicated. (B), Relapse-free survival and over-all survival for 66 patients with lung adenocarcinoma. 


\begin{tabular}{lcc}
\hline Characteristics & No. of patients & Mean expression level \\
\cline { 2 - 3 } Age & & $\boldsymbol{R} \boldsymbol{A I I 4}$ \\
$\mathbf{5 6 0}$ & 28 & 1.18 \\
$>\mathbf{6 0}$ & 41 & 2.12 \\
& P value & 0.24 \\
Gender & & 1.97 \\
Male & 22 & 1.63 \\
Female & 47 & P value \\
\hline
\end{tabular}

tissue samples ( $>2 \mathrm{~cm}$ away from the tumor) from patients who underwent lobectomy or pneumonectomy. To most genes, gene expression was down-regulated or slightly up-regulated in our patients (Supplementary Figure 2). However, we identified RAII4 as a new biomarker because $R A I 14$ was up-regulated in 31 of 71 patients (Figure $4 \mathrm{~A}$ ).

$R A I 14$ has not been applied as a biomarker or therapeutic target yet, there is even no medicine specifically targeting it. In a study performed by Yi-Chiung $\mathrm{Hsu}$ et al, although RAI14 was not studied separately, as 1 of 8 invasion-associated genes, it showed significant gene-drug correlation with paclitaxel, docetaxel and erlotinib and correlation with patients' relapse-free survival time [28]. In our study, it seemed that RAI14 expression was higher in elderly patients ( $>60$ years old) and male patients, but the differences were not significant (Table 1). The expression of the other 6 genes we tested was not related to patients' age or gender either (Supplementary-3). The effect of RAI14 on patients' prognosis (relapse-free survival, RFS and overall survival, OS) was also analyzed. It seemed that RAI14 expression up-regulated patients (RAI14_High) got better prognosis, however, the differences were not significant, neither on PFS nor on OS (Figure 4B).

\section{SE-induced $\boldsymbol{R} A I 14$ high expression inhibits cell proliferation}

As we performed RNA-seq in BEAS-2B instead of NHLF, to get a more reliable conclusion, we then identified SEs in BEAS-2B. Our ChIP-seq results indicated a SE located at $45 \mathrm{~kb}$ upstream of RAI14 in A549 but not in SPC-A1, SCH-1153, NHLF or BEAS-2B and the SE could give rise to extremely high expression of $R A I 14$ (Figure $5 \mathrm{~A}$, Figure 3D). To prove the hypothesis of SE-induced RAI14 high expression true, we analyzed the Hi-C data and ChIP-seq data of A549 from ENCODE and found frequent interactions between $R A I 14$ gene body and the upstream SE region, which indicated the up-regulated gene expression was caused by this upstream SE (Figure 5B).

To understand the biological function of RAI14, we infected BEAS-2B cells by lentivirus to stably express RAI14. RAI14, also known as NORPEG, has been reported to promote cell proliferation and shorten ovarian cancer cell cycle as a downstream gene of NR2F2 [29, 30]. However, in our study, over-expression of RAI14 could inhibit proliferation of BEAS-2B cells, which may result in better prognosis of RAI14 expression up-regulated patients (Figure 5C).

\section{DISCUSSION}

Precise diagnosis and targeted therapy are more and more attractive for lung cancer treatment. Even more and more genomic alterations were found, it's still hard to find new biomarker genes because most of these abnormalities are irrelevant with tumorigenesis. The discovery that $\mathrm{SE}$ in cancers usually associates with key oncogenes provides us a feasible method to look for new potential oncogenes [19]. Cancer cell could gain carcinogenic SEs through a variety of mechanisms during cancer pathogenesis [13]. Moreover, SEs in cancers are more sensitive to perturbation than typical enhancers (TEs), so the expression of associated genes is impaired more significantly than other genes [31-35]. Previous studies of SE render the strategies to inhibit the expression of SEassociated oncogenes by damaging their SEs.

ENCODE and Roadmap Epigenomics Project have gathered $\mathrm{H} 3 \mathrm{~K} 27 \mathrm{ac}$ ChIP-seq data of different cells and tissues, but SPC-A1 and SCH-1153 in our study are investigated for the first time [36-38]. In current studies, only a few known driver mutations are proved to be related to SE alterations. Oncogenic SEs mainly generate from gene fusions, non-coding region mutations, focal amplifications and deletions [39-41]. 
The deviation between cell line and tissue is a challenge in our study and also a problem to other researchers. In our study, even though most part of oncogenes showed significantly increased expression in cell, the expression status couldn't be verified in tissue. And RAI14 was up-regulated in 31 of 71 patients, but it was only associated with SE in A549. As the deviation is hard to eliminate, direct SE researches in tumor samples are necessary for more valuable discoveries and further clinical applications. Based on the comprehensive study of SE distribution and patients' characteristics, we can create new methods for tumor classification and prognosis prediction. For example, Lin et al have successfully found subgroup-specific SEs and revealed cellular

A

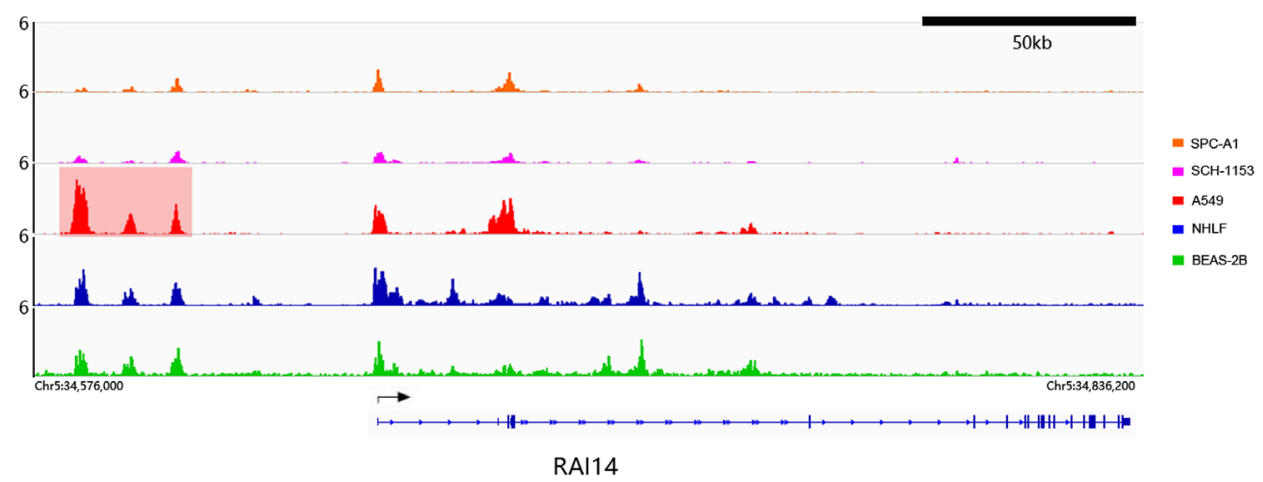

B

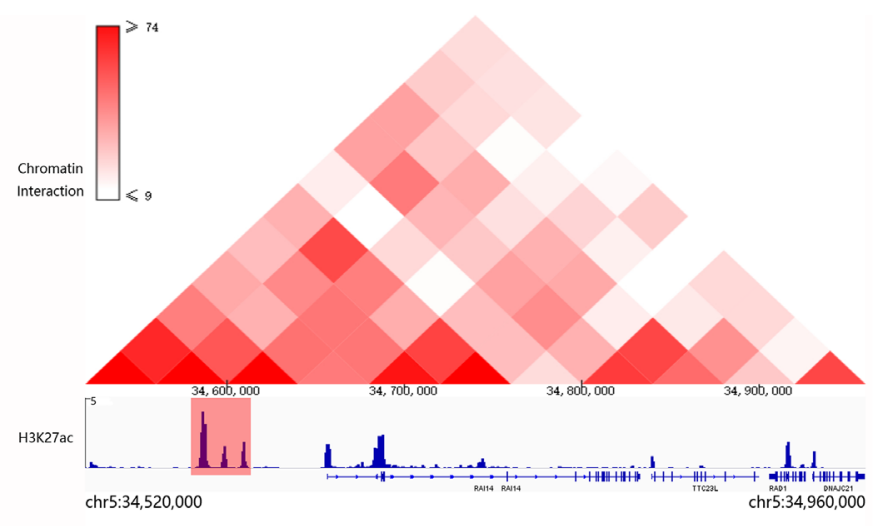

C

\section{Growth Curve}

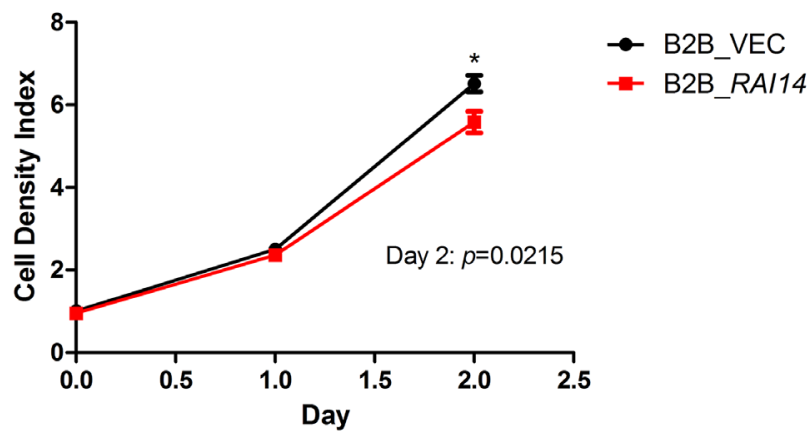

Figure 5: ChIP-seq binding profiles, Hi-C heat map at $\boldsymbol{R} \boldsymbol{A I 1 4}$ in A549 and growth curve. (A), ChIP-seq binding profiles of $\mathrm{H} 3 \mathrm{~K} 27 \mathrm{ac}$ at RAI14 in 5 cell lines as indicated. Gene model was depicted below the binding profiles. The SE was marked out with light red background. (B), Hi-C heat map and ChIP-seq binding profile of H3K27ac at RAI14 in A549. The color bar indicated the interaction frequency between two regions of chromatin. The SE associated with RAI14 is marked out with light red background. (C), Growth curve of RAI14 over-expression BEAS-2B cell and normal BEAS-2B cell. 
origins by analyzing SE-regulated TFs differences in medulloblastoma [42].

For the first time, we described the SE landscape in SPC-A1 and SCH-1153 and identified new SE-associated oncogenes. After verifying the expression of potential oncogenes in both cell lines and tissue samples, we finally found the potential of RAII4 as a new SE-associated oncogene and a biomarker for patients who were not suitable for TKIs treatment. Our method of oncogene discovery may be applied to study other cancers.

\section{MATERIALS AND METHODS}

\section{Cell lines and cell culture}

SPC-A1 is a commercial lung adenocarcinoma cell line derived from a Chinese patient without $E G F R$ mutations, $A L K$-fusions or KRAS mutations. SCH-1153 is a primary lung adenocarcinoma cell line derived from a KRAS mutation (G12C) positive Chinese patient in our department, which has been stably cultured for more than 50 generations. A549 is a commercial lung adenocarcinoma cell line derived from a KRAS mutation (G12S) positive Caucasian patient. BEAS-2B is a commercial human bronchial epithelial cell line we used to instead NHLF, since NHLF is primary normal human lung fibroblasts which is hard for us to acquire.

SPC-A1, SCH-1153 and A549 cells were cultured in RPMI-1640 medium (Corning, 10-040-CVR) suppled with 10\% fetal bovine serum (Gemini, 900-108), penicillin (100U/ml, gbico, 10378-016), streptomycin $(100 \mathrm{mg} / \mathrm{ml}$, gbico, 10378-016) and L-Glutamine (2mM, gbico, 10378016 ) at $37^{\circ} \mathrm{C}$ with $5 \% \mathrm{CO}_{2}$. BEAS-2B cells were cultured in DMEM medium (Corning, 10-013-CVR) suppled with $10 \%$ fetal bovine serum (Gemini, 900-108), penicillin (100U/ml, gbico, 10378-016), streptomycin (100mg/ $\mathrm{ml}$, gbico, 10378-016) and L-Glutamine (2mM, gbico, Corning, $10378-016$ ) at $37^{\circ} \mathrm{C}$ with $5 \% \mathrm{CO}_{2}$.

BEAS-2B cells were infected by RAII4-overexpression lentivirus for 48 hours and then cultured in DMEM medium with $1 \mathrm{ug} / \mathrm{ml}$ puromycin for 48 hours.

\section{ChIP-seq}

SPC-A1, SCH-1153 and BEAS-2B cells were collected when the confluence was about $90 \%$. Every 20-50 million cells were crosslinked in $20-50 \mathrm{ml}$ culture medium with $1 \%$ formaldehyde for 10 minutes at room temperature. The cell pellet was collected and washed with cold PBS, snap frozen in liquid nitrogen and stored at $-80^{\circ} \mathrm{C}$ or processed to next step. The cell pellet was dissolved in lysis buffer on ice for 30 minutes and sonicated with Bioruptor UCD-200 (Diagenode, Brussels). The supernatant was collected and mixed with $30 \mu \mathrm{l}$ H3K27ac antibody (Abcam, ab4729) coupled protein A dynabeads (Novex, 10002D) for 6 hours at $4^{\circ} \mathrm{C}$. The dynabeads were collected and washed as the previous method described [43]. The chromatin was eluted at $65^{\circ} \mathrm{C}$ and then reverse-crosslinked at $65^{\circ} \mathrm{C}$ over-night. The DNA was purified as user manual (Tiangen, DP214-03) and processed to library preparation for next-generation sequencing as instruction manual $\left(\mathrm{NEBNext}^{\mathbb{B}}\right.$ Ultra $^{\mathrm{TM}}$ II DNA Library Prep Kit for Illumina ${ }^{\circledR}$, E7645S). The sequencing was performed on HiSeq X Ten System (Illumina, Inc).

\section{ChIP-seq data analysis}

ChIP-seq data of A549 and NHLF was obtained from ENCODE (wgEncodeEH003118 and wgEncodeEH000097). ChIP-seq reads were aligned to human reference genome (build GRCh37/hg19) using BWA and peak calling was accomplished by MACS2 (Model-Based Analysis of ChIP-seq) to identify regions of H3K27ac enrichment over background (input) (Supplementary-6) [44]. We took a p-value threshold of $10^{-9}$ in data analysis. We used IGV to visualize the bigwig files $[45,46]$. We used HOMER to identify super enhancers, which emulated the original strategy used by the Young lab [19, 20,47]. The peaks in $12.5 \mathrm{~kb}$ were stitched together into larger regions and the signal score was measured by their normalized $\mathrm{H} 3 \mathrm{~K} 27 \mathrm{ac}$ reads and input reads. Then all regions were ranked by their signal score, and the region passed the point where the slope was 1 was classified as SE. All SE regions were annotated to the nearest Ensemble gene using HOMER. H3K27ac enrichment difference was analyzed with GFOLD [48].

\section{Hi-C data analysis}

Hi-C data of A549 was obtained from ENCODE3, generated by Dekker Laboratory (ENCFF478EAB, ENCFF319AST, ENCFF805BPJ and ENCFF582XKW). The heat map was generated by 3D Genome Browser (http://www.3dgenome.org.).

\section{Tissue samples}

We surgically harvested 71 lung adenocarcinoma samples and paired adjacent normal tissue samples $(>2$ $\mathrm{cm}$ away from the tumor) from patients who underwent lobectomy or pneumonectomy from August 2011 to January 2013. None received preoperative treatments. The information of patients was listed in Supplementary-4. The consent form was signed by every patient or his/ her legal representative. The study was approved by the Ethics Committee of Shanghai Cancer Hospital of Fudan University. After resection, part of each tissue was immediately frozen in liquid nitrogen for RNA extraction.

\section{RNA extraction and real-time PCR}

Cell and tissue samples were collected and dissolved in TRNzol (Tiangen, DP405) for total RNA extraction 
as user manual. For each sample, $2 \mu \mathrm{g}$ total RNA was reversely transcribed using FastQuant RT Kit (Tiangen, KR106). The primer sequences for real-time PCR were listed in Supplementary-5. SE-associated genes and GAPDH were amplified for 40 cycles on QuantStudio ${ }^{\mathrm{TM}} 6$ Flex (Applied Biosystems, USA) using SuperReal PreMix Plus (SYBR Green, Tiangen, FP205). The following program: $95^{\circ} \mathrm{C}$ for 15 minutes, $95^{\circ} \mathrm{C}$ for $10 \mathrm{~s}, 60^{\circ} \mathrm{C}$ for $32 \mathrm{~s}$ was applied for amplification. Quantification was calculated using comparative $\mathrm{Ct}$ method. Gene expression was firstly normalized by the $G A P D H$ expression in each tissue sample and expression status of each patient was calculated by the following method: (normalized expression in the tumor)/ (normalized expression in normal tissue).

\section{RNA-seq and RNA-seq data analysis}

RNA-seq libraries were prepared as instruction manual (NEBNext ${ }^{\circledR}$ Ultra $^{\mathrm{TM}}$ RNA Library Prep Kit for Illumina $^{\circledR}$, E7530S). The sequencing was performed on HiSeq X Ten System (Illumina, Inc). RNA-seq reads were aligned to human reference genome (build GRCh37/ hg19) using STAR [49]. Expression levels of genes and transcripts were compared using Cufflinks [50].

\section{Growth curve}

CCK8 kit (Yise, CK800-100) was used to make growth curves as user manual. Cells were cultured in 96 well plate and cell density was detected at day 0 , day 1 and day 2 for each well.

\section{Statistical analysis}

Statistical comparisons of groups defined by patients' clinical features with respect to the expression levels of the genes were based on the Unpaired T-test for two groups. All analysis were performed by GraphPad Prism 5 (GraphPad Software, Inc, CA 92037 USA). Statistical comparisons of survival curves were based on Gehan-Breslow-Wilcoxon Test. Statistical comparisons of cell density were based on the Unpaired T-test for two groups. For all the tests, 3 significance levels ( ${ }^{*}, \mathrm{P}<0.05$; $\left.{ }^{* *}, \mathrm{P}<0.01{ }^{* * *}, \mathrm{P}<0.001\right)$ were applied.

\section{Author contributions}

Conception and design: C.Yuan, Y.Sun

Development of methodology: C.Yuan, M.Kuang

Acquisition of data: C.Yuan, H.Hu

Analysis and interpretation of data: C.Yuan, H.Hu, M.Kuang, X.Tao

Writing, review, and/or revision of the manuscript: all authors

Study supervision: Y.Sun, Y.Zhang, H.Chen

\section{CONFLICTS OF INTEREST}

No potential conflicts of interest were disclosed.

\section{FUNDING}

This work was supported by the National Natural Science Foundation of China (No.81330056; No.81572253; No.81372525; No.81572264), the National Science Fund for Outstanding Young Scholars (No.81422029); the Chinese Minister of Science and Technology grant (2016YFA0501800, 2017YFA0505500) and Science and Technology Commission of Shanghai Municipality (15ZR1407800).

\section{REFERENCES}

1. Chen W, Zheng R, Baade PD, Zhang S, Zeng H, Bray F, Jemal A, Yu XQ, He J. Cancer statistics in China, 2015. CA Cancer J Clin. 2016; 66: 115-32. doi: 10.3322/caac.21338.

2. Sharma SV, Bell DW, Settleman J, Haber DA. Epidermal growth factor receptor mutations in lung cancer. Nat Rev Cancer. 2007; 7: 169-81. doi: 10.1038/nrc2088.

3. Rosell R, Moran T, Queralt C, Porta R, Cardenal F, Camps C, Majem M, Lopez-Vivanco G, Isla D, Provencio M, Insa A, Massuti B, Gonzalez-Larriba JL, et al. Screening for epidermal growth factor receptor mutations in lung cancer. N Engl J Med. 2009; 361: 958-67. doi: 10.1056/ NEJMoa0904554.

4. Wu JY, Yu CJ, Yang CH, Wu SG, Chiu YH, Gow CH, Chang YC, Hsu YC, Wei PF, Shih JY, Yang PC. First- or second-line therapy with gefitinib produces equal survival in non-small cell lung cancer. Am J Respir Crit Care Med. 2008; 178: 847-53. doi: 10.1164/rccm.200803-389OC.

5. Soda M, Choi YL, Enomoto M, Takada S, Yamashita Y, Ishikawa S, Fujiwara S, Watanabe H, Kurashina K, Hatanaka H, Bando M, Ohno S, Ishikawa Y, et al. Identification of the transforming EML4-ALK fusion gene in non-small-cell lung cancer. Nature. 2007; 448: 561-6. doi: 10.1038 /nature 05945 .

6. Cappuzzo F, Ciuleanu T, Stelmakh L, Cicenas S, Szczésna A, Juhász E, Esteban E, Molinier O, Brugger W, Melezínek I, Klingelschmitt G, Klughammer B, Giaccone G. Erlotinib as maintenance treatment in advanced non-small-cell lung cancer: a multicentre, randomised, placebo-controlled phase 3 study. The Lancet Oncology. 2010; 11: 521-9. doi: 10.1016/s1470-2045(10)70112-1.

7. Mao C, Qiu LX, Liao RY, Du FB, Ding H, Yang WC, Li J, Chen Q. KRAS mutations and resistance to EGFR-TKIs treatment in patients with non-small cell lung cancer: a meta-analysis of 22 studies. Lung Cancer. 2010; 69: 272-8. doi: 10.1016/j.lungcan.2009.11.020.

8. Xia N, An J, Jiang QQ, Li M, Tan J, Hu CP. Analysis of EGFR, EML4-ALK, KRAS, and c-MET mutations in 
Chinese lung adenocarcinoma patients. Exp Lung Res. 2013; 39: 328-35. doi: 10.3109/01902148.2013.819535.

9. Kenessey I, Koi K, Horvath O, Cserepes M, Molnar D, Izsak V, Dobos J, Hegedus B, Tovari J, Timar J. KRAS-mutation status dependent effect of zoledronic acid in human nonsmall cell cancer preclinical models. Oncotarget. 2016; 7: 79503-14. doi: 10.18632/oncotarget.12806.

10. Schiller JH, Adak S, Feins RH, Keller SM, Fry WA, Livingston RB, Hammond ME, Wolf B, Sabatini L, Jett J, Kohman L, Johnson DH. Lack of prognostic significance of p53 and K-ras mutations in primary resected non-smallcell lung cancer on E4592: a Laboratory Ancillary Study on an Eastern Cooperative Oncology Group Prospective Randomized Trial of Postoperative Adjuvant Therapy. J Clin Oncol. 2001; 19: 448-57. doi: 10.1200/JCO.2001.19.2.448.

11. Pao W, Wang TY, Riely GJ, Miller VA, Pan Q, Ladanyi M, Zakowski MF, Heelan RT, Kris MG, Varmus HE. KRAS mutations and primary resistance of lung adenocarcinomas to gefitinib or erlotinib. PLoS Med. 2005; 2: e17. doi: 10.1371/journal.pmed.0020017.

12. Blumenschein GR Jr, Smit EF, Planchard D, Kim DW, Cadranel J, De Pas T, Dunphy F, Udud K, Ahn MJ, Hanna NH, Kim JH, Mazieres J, Kim SW, et al. A randomized phase II study of the MEK1/MEK2 inhibitor trametinib (GSK1120212) compared with docetaxel in KRAS-mutant advanced non-small-cell lung cancer (NSCLC)dagger. Ann Oncol. 2015; 26: 894-901. doi: 10.1093/annonc/mdv072.

13. Hnisz D, Abraham BJ, Lee TI, Lau A, Saint-Andre V, Sigova AA, Hoke HA, Young RA. Super-enhancers in the control of cell identity and disease. Cell. 2013; 155: 934-47. doi: 10.1016/j.cell.2013.09.053.

14. Heintzman ND, Stuart RK, Hon G, Fu Y, Ching CW, Hawkins RD, Barrera LO, Van Calcar S, Qu C, Ching KA, Wang W, Weng Z, Green RD, et al. Distinct and predictive chromatin signatures of transcriptional promoters and enhancers in the human genome. Nat Genet. 2007; 39: 3118. doi: 10.1038/ng1966.

15. Ernst J, Kheradpour P, Mikkelsen TS, Shoresh N, Ward LD, Epstein CB, Zhang X, Wang L, Issner R, Coyne M, $\mathrm{Ku}$ M, Durham T, Kellis M, et al. Mapping and analysis of chromatin state dynamics in nine human cell types. Nature. 2011; 473: 43-9. doi: 10.1038/nature09906.

16. Creyghton MP, Cheng AW, Welstead GG, Kooistra T, Carey BW, Steine EJ, Hanna J, Lodato MA, Frampton GM, Sharp PA, Boyer LA, Young RA, Jaenisch R. Histone H3K27ac separates active from poised enhancers and predicts developmental state. Proc Natl Acad Sci U S A. 2010; 107: 21931-6. doi: 10.1073/pnas.1016071107.

17. Zhu J, Adli M, Zou JY, Verstappen G, Coyne M, Zhang X, Durham T, Miri M, Deshpande V, De Jager PL, Bennett DA, Houmard JA, Muoio DM, et al. Genome-wide chromatin state transitions associated with developmental and environmental cues. Cell. 2013; 152: 642-54. doi: 10.1016/j.cell.2012.12.033.
18. Rada-Iglesias A, Bajpai R, Swigut T, Brugmann SA, Flynn RA, Wysocka J. A unique chromatin signature uncovers early developmental enhancers in humans. Nature. 2011; 470: 279-83. doi: 10.1038/nature09692.

19. Loven J, Hoke HA, Lin CY, Lau A, Orlando DA, Vakoc CR, Bradner JE, Lee TI, Young RA. Selective inhibition of tumor oncogenes by disruption of super-enhancers. Cell. 2013; 153: 320-34. doi: 10.1016/j.cell.2013.03.036.

20. Whyte WA, Orlando DA, Hnisz D, Abraham BJ, Lin CY, Kagey MH, Rahl PB, Lee TI, Young RA. Master transcription factors and mediator establish super-enhancers at key cell identity genes. Cell. 2013; 153: 307-19. doi: 10.1016/j.cell.2013.03.035.

21. Brown JD, Lin CY, Duan Q, Griffin G, Federation A, Paranal RM, Bair S, Newton G, Lichtman A, Kung A, Yang T, Wang $\mathrm{H}$, Luscinskas FW, et al. NF-kappaB directs dynamic super enhancer formation in inflammation and atherogenesis. Mol Cell. 2014; 56: 219-31. doi: 10.1016/j.molcel.2014.08.024.

22. Nabet B, Ó Broin P, Reyes JM, Shieh K, Lin CY, Will CM, Popovic R, Ezponda T, Bradner JE, Golden AA, Licht JD. Deregulation of the Ras-Erk Signaling Axis Modulates the Enhancer Landscape. Cell Rep. 2015; 12: 1300-13. doi: 10.1016/j.celrep.2015.06.078.

23. Jiang YY, Lin DC, Mayakonda A, Hazawa M, Ding LW, Chien WW, Xu L, Chen Y, Xiao JF, Senapedis W, Baloglu E, Kanojia D, Shang L, et al. Targeting super-enhancer-associated oncogenes in oesophageal squamous cell carcinoma. Gut. 2017; 66: 1358-68. doi: 10.1136/gutjnl-2016-311818.

24. Curry MC, Peters AA, Kenny PA, Roberts-Thomson SJ, Monteith GR. Mitochondrial calcium uniporter silencing potentiates caspase-independent cell death in MDA-MB-231 breast cancer cells. Biochem Biophys Res Commun. 2013; 434: 695-700. doi: 10.1016/j. bbrc.2013.04.015.

25. Vaishnavi A, Capelletti M, Le AT, Kako S, Butaney M, Ercan D, Mahale S, Davies KD, Aisner DL, Pilling AB, Berge EM, Kim J, Sasaki H, et al. Oncogenic and drugsensitive NTRK1 rearrangements in lung cancer. Nat Med. 2013; 19: 1469-72. doi: 10.1038/nm.3352.

26. Meijer D, Jansen MP, Look MP, Ruigrok-Ritstier K, van Staveren IL, Sieuwerts AM, van Agthoven T, Foekens JA, Dorssers LC, Berns EM. TSC22D1 and PSAP predict clinical outcome of tamoxifen treatment in patients with recurrent breast cancer. Breast Cancer Res Treat. 2009; 113: 253-60. doi: 10.1007/s10549-008-9934-3.

27. Park SY, Choi HK, Seo JS, Yoo JY, Jeong JW, Choi Y, Choi KC, Yoon HG. DNAJB1 negatively regulates MIG6 to promote epidermal growth factor receptor signaling. Biochim Biophys Acta. 2015; 1853: 2722-30. doi: 10.1016/j.bbamcr.2015.07.024.

28. Hsu YC, Chen HY, Yuan S, Yu SL, Lin CH, Wu G, Yang $\mathrm{PC}$, Li KC. Genome-wide analysis of three-way interplay among gene expression, cancer cell invasion and anticancer compound sensitivity. BMC Med. 2013; 11: 106. doi: 10.1186/1741-7015-11-106. 
29. Kutty RK, Chen S, Samuel W, Vijayasarathy C, Duncan T, Tsai JY, Fariss RN, Carper D, Jaworski C, Wiggert B. Cell density-dependent nuclear/cytoplasmic localization of NORPEG (RAI14) protein. Biochem Biophys Res Commun. 2006; 345: 1333-41. doi: 10.1016/j.bbrc.2006.04.184.

30. Hawkins SM, Loomans HA, Wan YW, Ghosh-Choudhury T, Coffey D, Xiao W, Liu Z, Sangi-Haghpeykar H, Anderson ML. Expression and functional pathway analysis of nuclear receptor NR2F2 in ovarian cancer. J Clin Endocrinol Metab. 2013; 98: E1152-62. doi: 10.1210/jc.2013-1081.

31. Christensen CL, Kwiatkowski N, Abraham BJ, Carretero J, Al-Shahrour F, Zhang T, Chipumuro E, Herter-Sprie GS, Akbay EA, Altabef A, Zhang J, Shimamura T, Capelletti M, et al. Targeting transcriptional addictions in small cell lung cancer with a covalent CDK7 inhibitor. Cancer Cell. 2014; 26: 909-22. doi: 10.1016/j.ccell.2014.10.019.

32. Pelish HE, Liau BB, Nitulescu II, Tangpeerachaikul A, Poss ZC, Da Silva DH, Caruso BT, Arefolov A, Fadeyi O, Christie AL, Du K, Banka D, Schneider EV, et al. Mediator kinase inhibition further activates super-enhancerassociated genes in AML. Nature. 2015; 526: 273-6. doi: 10.1038/nature14904.

33. Chapuy B, McKeown MR, Lin CY, Monti S, Roemer MG, Qi J, Rahl PB, Sun HH, Yeda KT, Doench JG, Reichert E, Kung AL, Rodig SJ, et al. Discovery and characterization of super-enhancer-associated dependencies in diffuse large B cell lymphoma. Cancer Cell. 2013; 24: 777-90. doi: 10.1016/j.ccr.2013.11.003.

34. Kwiatkowski N, Zhang T, Rahl PB, Abraham BJ, Reddy J, Ficarro SB, Dastur A, Amzallag A, Ramaswamy S, Tesar B, Jenkins CE, Hannett NM, McMillin D, et al. Targeting transcription regulation in cancer with a covalent CDK7 inhibitor. Nature. 2014; 511: 616-20. doi: 10.1038/ nature13393.

35. Chipumuro E, Marco E, Christensen CL, Kwiatkowski N, Zhang T, Hatheway CM, Abraham BJ, Sharma B, Yeung C, Altabef A, Perez-Atayde A, Wong KK, Yuan GC, et al. CDK7 inhibition suppresses super-enhancer-linked oncogenic transcription in MYCN-driven cancer. Cell. 2014; 159: 1126-39. doi: 10.1016/j.cell.2014.10.024.

36. Roadmap Epigenomics C, Kundaje A, Meuleman W, Ernst J, Bilenky M, Yen A, Heravi-Moussavi A, Kheradpour P, Zhang Z, Wang J, Ziller MJ, Amin V, Whitaker JW, et al. Integrative analysis of 111 reference human epigenomes. Nature. 2015; 518: 317-30. doi: 10.1038/nature14248.

37. Consortium EP. An integrated encyclopedia of DNA elements in the human genome. Nature. 2012; 489: 57-74. doi: 10.1038/nature11247.

38. Thurman RE, Rynes E, Humbert R, Vierstra J, Maurano MT, Haugen E, Sheffield NC, Stergachis AB, Wang H, Vernot B, Garg K, John S, Sandstrom R, et al. The accessible chromatin landscape of the human genome. Nature. 2012; 489: 75-82. doi: 10.1038/nature11232.

39. Northcott PA, Lee C, Zichner T, Stutz AM, Erkek S, Kawauchi D, Shih DJ, Hovestadt V, Zapatka M, Sturm D,
Jones DT, Kool M, Remke M, et al. Enhancer hijacking activates GFI1 family oncogenes in medulloblastoma. Nature. 2014; 511: 428-34. doi: 10.1038/nature13379.

40. Zhang X, Choi PS, Francis JM, Imielinski M, Watanabe $\mathrm{H}$, Cherniack AD, Meyerson M. Identification of focally amplified lineage-specific super-enhancers in human epithelial cancers. Nat Genet. 2016; 48: 176-82. doi: 10.1038/ng.3470.

41. Mansour MR, Abraham BJ, Anders L, Berezovskaya A, Gutierrez A, Durbin AD, Etchin J, Lawton L, Sallan SE, Silverman LB, Loh ML, Hunger SP, Sanda T, et al. Oncogene regulation. An oncogenic super-enhancer formed through somatic mutation of a noncoding intergenic element. Science. 2014; 346: 1373-7. doi: 10.1126/ science. 1259037.

42. Lin CY, Erkek S, Tong Y, Yin L, Federation AJ, Zapatka M, Haldipur P, Kawauchi D, Risch T, Warnatz HJ, Worst BC, Ju B, Orr BA, et al. Active medulloblastoma enhancers reveal subgroup-specific cellular origins. Nature. 2016; 530: 57-62. doi: 10.1038/nature16546.

43. Schmidt D, Wilson MD, Spyrou C, Brown GD, Hadfield J, Odom DT. ChIP-seq: using high-throughput sequencing to discover protein-DNA interactions. Methods. 2009; 48: 240-8. doi: 10.1016/j.ymeth.2009.03.001.

44. Li H, Durbin R. Fast and accurate long-read alignment with Burrows-Wheeler transform. Bioinformatics. 2010; 26: 589-95. doi: 10.1093/bioinformatics/btp698.

45. Robinson JT, Thorvaldsdottir H, Winckler W, Guttman M, Lander ES, Getz G, Mesirov JP. Integrative genomics viewer. Nat Biotechnol. 2011; 29: 24-6. doi: 10.1038/ nbt.1754.

46. Thorvaldsdottir H, Robinson JT, Mesirov JP. Integrative Genomics Viewer (IGV): high-performance genomics data visualization and exploration. Brief Bioinform. 2013; 14 : 178-92. doi: 10.1093/bib/bbs017.

47. Heinz S, Benner C, Spann N, Bertolino E, Lin YC, Laslo P, Cheng JX, Murre C, Singh H, Glass CK. Simple combinations of lineage-determining transcription factors prime cis-regulatory elements required for macrophage and B cell identities. Mol Cell. 2010; 38: 576-89. doi: 10.1016/j. molcel.2010.05.004.

48. Feng J, Meyer CA, Wang Q, Liu JS, Shirley Liu X, Zhang Y. GFOLD: a generalized fold change for ranking differentially expressed genes from RNA-seq data. Bioinformatics. 2012; 28: 2782-8. doi: 10.1093/bioinformatics/bts515.

49. Dobin A, Davis CA, Schlesinger F, Drenkow J, Zaleski C, Jha S, Batut P, Chaisson M, Gingeras TR. STAR: ultrafast universal RNA-seq aligner. Bioinformatics. 2013; 29: 15-21. doi: 10.1093/bioinformatics/bts635.

50. Trapnell C, Roberts A, Goff L, Pertea G, Kim D, Kelley DR, Pimentel H, Salzberg SL, Rinn JL, Pachter L. Differential gene and transcript expression analysis of RNA-seq experiments with TopHat and Cufflinks. Nat Protoc. 2012; 7: 562-78. doi: 10.1038/nprot.2012.016. 